\title{
Epidemiology of oral HPV in the oral mucosa in women without signs of oral disease from Yucatan, Mexico
}

\author{
María del Refugio Gonzalez-Losa ${ }^{1}$, Ernesto Soria Barrera ${ }^{2}$, Verónica Herrera-Pech ${ }^{1}$, \\ Laura Conde-Ferráez ${ }^{1}$, Marylin Puerto-Solís ${ }^{1}$, Guadalupe Ayora-Talavera ${ }^{1}$ \\ ${ }^{1}$ Laboratorio de Virología, Centro de Investigaciones Regionales "Dr. Hideyo Noguchi", \\ Universidad Autónoma de Yucatán, Yucatán, México. \\ ${ }^{2}$ Centro Materno Infantil, Secretaria de Salud del Estado de Yucatán, Yucatán, México.
}

Submitted: September 13, 2013; Approved: June 6, 2014.

\begin{abstract}
High-risk human papillomaviruses (HR-HPV) are considered necessary for the development of cervical cancer. Furthermore, there is no doubt that some types of oral squamous cell carcinoma are associated with HR-HPV. The epidemiology of oral HPV infections in healthy subjects remains unclear due to a lack of knowledge. The objective of this study was to investigate the epidemiology of human papillomavirus infections of the oral mucosa without pathology. A cross-sectional study was performed; samples from 390 women seeking prenatal care, Pap smears, family planning or gynecological diseases were studied. Oral cells were collected by direct swab sampling. Information regarding sociodemographic status, sexual behavior, infectious diseases, contraceptive history and tobacco and alcohol consumption were obtained through direct interviews. HPV and genotypes were detected by type-specific polymerase chain reaction. Our results revealed that $14 \%$ of the women studied had an oral HPV infection. Women $\leq 20$ years of age had the highest HPV prevalence (24.5\%). In total, seven genotypes were identified, including the high-risk genotypes 16, 18, 58 and 59 and the low-risk genotypes 6,81 and 13, the latter of which is a type exclusive to oral mucosa. Sexual behavior was not associated with the presence of genital HPV types in the oral mucosa. Genital HPV types were present in the oral mucosa of women without associated clinical manifestations; however, sexual behavior was not associated with infection, and therefore others routes of transmission should be explored.
\end{abstract}

Key words: Papillomavirus, oral mucosa, HPV13, Mexico.

\section{Introduction}

Human papillomavirus (HPV) belongs to a large family of small non-enveloped double stranded DNA viruses with an $8 \mathrm{~Kb}$ genome. These viruses infect basal cells of the squamous epithelium of the skin or mucosa (López-Saavedra, and Lizano-Soberón., 2006).

More than $100 \mathrm{HPV}$ types have been described, 35\% of which are generally found in the genitals. Genital HPV has been classified into high risk types $(16,18,31,33,35,39$, $45,51,52,56,58,59,68,73$ and 82); probable high-risk types (26, 53, and 66) and low-risk types $(6,11,40,42,43$, $44,54,61,70,72,81$, and CP6108) according to their associ- ation with neoplasias (De Villers et al., 2004; Lizano et al., 2009). Today, there is no doubt that oncogenic HPV infection is necessary for the development cervical cancer (Walboomers et al., 1999).

During the past two decades, numerous studies have associated HPV infection with other epithelial neoplasias, such as head and neck squamous cell carcinoma (HNSCC) (D'Souzaa et al., 2011).

Oral cancer is a subtype of HNSCC constituting 3\% and $2 \%$ of all malignant neoplasms of males and females, respectively. During the past decade, the incidence has increased nearly five-fold in subjects younger than 40 years old (Khalili, 2008). 
Although oral cancer has been associated with tobacco and alcohol consumption, a fraction of these neoplasias are associated with HPV infection, primarily among individuals without other risk factors (D'Souzaa et al., 2011; Mao et al., 2004; Smith et al., 2004).

The presence of HPV DNA in HNSCC has motivated the study of HPV in the oral mucosa in different groups. The prevalence in subjects without oral pathology is highly variable and depend on the methodology used, the populations studied and sampling methods (Galvão and Bussoloti., 2006). To understand the natural history of HPV infection in the oral mucosa, epidemiologic studies are required. The aim of this study was to describe the epidemiology of HPV in normal oral mucosa of women without oral lesions.

\section{Materials and Methods}

\section{Study population}

This report is a cross-sectional study describing the epidemiology of oral HPV infections in a group of women seen for Pap smears, family planning, pregnancy or gynecological diseases at the public hospital Centro Materno Infantil, Secretaria de Salud, in Merida, Yucatan, Mexico during 2009. The women who utilize this facility are low income native Mexicans of urban, suburban or rural origin without social security.

\section{Ethical considerations}

This project was approved by the scientific and bioethical committee of Centro de Investigaciones Regionales "Dr. Hideyo Noguchi", Universidad Autónoma de Yucatan. All participants signed an informed consent.

\section{Specimen and data collection}

After oral clinical evaluation, all women without lesions were sampled. Buccal mucosa cells were collected by direct swab sampling and then agitated in $5 \mathrm{~mL}$ of cold PBS containing antibiotics $(500 \mathrm{U} / \mathrm{mL}$ penicillin, $500 \mu \mathrm{g} / \mathrm{mL}$ streptomycin and $4 \mathrm{mg} / \mathrm{mL}$ gentamicin).

Information about sociodemographic status, sexual behavior, infectious diseases, contraceptive history and tobacco and alcohol consumption were obtained through a direct interview with patients conducted by an experienced social worker.

\section{HPV DNA detection}

DNA was extracted using the DNeasy Blood and Tissue Kit (QIAGEN) according to the manufacturer's instructions by experienced personnel. $\beta$ globin was amplified as a control for DNA quality using the primers PC04 and GH20 (260 bp amplicon) (Saiki et al., 1985).

To confirm HPV infection, a nested PCR assay was performed using MY09 and MY11 as outer primers and GP5/GP6 as inner primers. A $3 \mu \mathrm{L}$ aliquot of the amplicon product from the first round of amplification was used as the template for a second round of PCR using the primers GP5/GP6 (150 bp) (Qu et al., 1997).

\section{HPV typing}

High-risk genotypes (16, 18, 31, 59, 45, 33, 35, 58, 52, and 56) were detected using a nested multiplex PCR assay that amplifies the E6 and E7 genes. Three degenerate consensus primers were used for the first round of amplification. Type specific primers were used for multiplex nested PCR according to a previously published method (Sotlar et al., 2004). Previously typed samples and a PCR mix without DNA were used as positive and negative controls respectively. All PCR reactions were performed on a DNA Engine thermal cycler (DYAD), and amplicons were visualized on $8 \%$ polyacrylamide gels using a 100 bp molecular weight marker (Invitrogen).

\section{Sequencing}

Samples that did not amplify with any type specific primers were typed by direct sequencing. GP5/GP6 amplicons were gel purified using the Wizard SV Gel and PCR Clean-Up system (Promega) and sequenced using the dideoxyterminal method on 3700 DNA Analysis equipment (Applied Biosystems) at the Laboratorio Nacional de Genómica CINVESTAV Irapuato, Mexico. The sequences were analyzed using Chromas bioinformatics software and were Blasted against NCBI nucleotide databases.

\section{Database analyses}

The variables studied were input into an SPSS database. The frequencies of variables and chi squares were calculated. Chi squares were calculated to determine association between HPV prevalence and age, age at first intercourse, number of sexual partners, condom use, oral sex, anal sex, the presence of genital warts in women and/or partners, smoking, passive tobacco exposure and alcohol consumption.

For the analysis, the following variables were categorized as follows: condom use: always or occasionally $v s$. never; age of first intercourse: $<18$ years $v s$. $\geq 18$ years; number of sexual partners: $\leq 2 v s . \geq 3$. P-values $\leq 0.05$ were considered statistically significant.

\section{Results}

\section{Characteristics of the study population}

In total, 390 women were included in this study. The mean age of the study population was 31 years (15-71), 39\% were $\leq 25$ years old, and $79 \%$ lived in urban areas. At the time of the study $73 \%$ of participants were housewives, $3 \%$ were sex workers, and $24.3 \%$ were working in various fields. Among the study participants, $15 \%$ had no formal education. A total of $19 \%$ of the participants' sexual partners lived in another town for work, $6.4 \%$ did not have a sexual partner at the time of the study, and four women had never had sex. 
With respect to sexual behavior, $62 \%$ of participants had their first intercourse before the age of $18,97 \%$ had $\leq 3$ sexual partners in their lifetimes and $63 \%$ engaged in both oral and vaginal sex, $38 \%$ in both anal and vaginal sex and $31 \%$ in oral, anal and vaginal sex.

A total of $5 \%$ of the women had a history of sexually transmitted diseases and $2.8 \%$ and $5 \%$ of the women and their sexual partners, respectively, had genital warts at the time of the study. Information regarding genital warts was reported by the women, and no clinical evaluation was performed. Finally, $10 \%$ of participants smoked, $48 \%$ reported passive tobacco exposure, and 64\% reported alcohol consumption (Table 1).

\section{HPV infections}

Seven samples were excluded because $\beta$ globin could not be amplified. Therefore, 383 samples underwent HPV detection.

HPV was successfully amplified from $14.8 \%$ of the samples (57/383); $36.8 \%$ (21/57) were positive using the MY09 and MY11 primers, and 63.1\% (36/57) were positive after a second round of amplification with the GP5/GP6 primers.

Seven genotypes were identified among $47 \mathrm{HPV}$ positive samples: the high-risk $16,18,58$ and 59 genotypes and the low-risk 6, 81 and 13 genotypes, the latter of which only infects the oral mucosa. Two dual infections were identified: $13 / 16$ and $58 / 59$. Ten samples were not tested for genotypes due to technical issues.

Table 1 - Charateristics of 390 Mexican women seen for Pap smears, family planning, pregnancy or gynecological diseases.

\begin{tabular}{|c|c|c|}
\hline Characteristic & Number & $\%$ \\
\hline \multicolumn{3}{|l|}{ Age } \\
\hline$<25$ & 141 & 36 \\
\hline $25-34$ & 102 & 26 \\
\hline $35-44$ & 87 & 22 \\
\hline $45-54$ & 43 & 11 \\
\hline $55-64$ & 15 & 4 \\
\hline $65+$ & 2 & 1 \\
\hline \multicolumn{3}{|l|}{ Residence } \\
\hline Rural & 79 & 20 \\
\hline Urban & 311 & 80 \\
\hline \multicolumn{3}{|l|}{ Education } \\
\hline None & 60 & 15 \\
\hline Elementary & 111 & 29 \\
\hline Middle-school & 148 & 38 \\
\hline High-school & 31 & 8 \\
\hline College, University, Technical & 40 & 10 \\
\hline \multicolumn{3}{|l|}{ Occupation } \\
\hline Student & 14 & 4 \\
\hline Housewife & 286 & 73 \\
\hline Employee & 78 & 20 \\
\hline Sex worker & 12 & 3 \\
\hline \multicolumn{3}{|l|}{ *Age of first intercourse (years) } \\
\hline$<18$ & 242 & 63 \\
\hline$\geq 18$ years & 144 & 37 \\
\hline \multicolumn{3}{|c|}{ Lifetime number of sexual partners } \\
\hline 0 & 4 & 1 \\
\hline 1 & 173 & 44 \\
\hline 2 & 93 & 24 \\
\hline$\geq 3$ & 120 & 31 \\
\hline \multicolumn{3}{|l|}{ *Oral and vaginal sex } \\
\hline YES & 247 & 64 \\
\hline
\end{tabular}

\begin{tabular}{|c|c|c|}
\hline Characteristic & Number & $\%$ \\
\hline $\mathrm{NO}$ & 138 & 36 \\
\hline Data lost & 1 & \\
\hline \multicolumn{3}{|c|}{ *Anal and vaginal intercourse } \\
\hline YES & 147 & 38 \\
\hline NO & 239 & 62 \\
\hline \multicolumn{3}{|l|}{ *Condom use } \\
\hline Never & 211 & 55 \\
\hline Ever & 154 & 40 \\
\hline Always & 21 & 5 \\
\hline \multicolumn{3}{|c|}{ *Sexual partner with genital warts } \\
\hline YES & 21 & 5 \\
\hline NO & 365 & 95 \\
\hline \multicolumn{3}{|c|}{ Women with genital warts } \\
\hline YES & 15 & 4 \\
\hline NO & 371 & 96 \\
\hline \multicolumn{3}{|c|}{ Sexual transmitted disease history } \\
\hline YES & 21 & 5 \\
\hline NO & 365 & 95 \\
\hline \multicolumn{3}{|c|}{ Alcohol consumption } \\
\hline YES & 257 & 66 \\
\hline NO & 133 & 35 \\
\hline \multicolumn{3}{|l|}{ Smoking } \\
\hline YES & 39 & 10 \\
\hline NO & 351 & 90 \\
\hline \multicolumn{3}{|c|}{ Passive tobacco exposure } \\
\hline YES & 188 & 48 \\
\hline NO & 202 & 52 \\
\hline
\end{tabular}

None: analphabets; elementary: 6 years after preschool; middle-school: 3 years after elementary; high-school: 3 years after high-school; college/university/technical: includes studies after high school and/or professional training after middle-school. * 4 were excluded due they never have had intercourse. 
Considering only typed samples, the frequency of each genotype was as follows:

HPV13, 70\% (33/47); HPV6, 13\% (6/47); HPV58 and 16, 6.3\% (3/47) each; HPV81, 59 and 18, 2\% (1/47) each. Altogether, $17 \%$ of the HPV-positive women were infected with high risk HPV.

The overall distribution of HPV according to age was as follows: $\leq 20$ years, $24.5 \% ; 21-25,21 \% ; 26-30,17.5 \% ; 31-35$, $12.3 \%$; 36-40, 8.7\%; 41-45, 7\%; 46-50, 7\%; and $\geq 51,1.7 \%$ (Table 1).

The epidemiological data for the HPV positive women revealed an age range of 16-57 years, with a mean of 29 years. The level of education for $85 \%$ of study participants was lower than high school, 46 were housewives, 2 were students, 8 worked in several fields and one was a sex worker.

Data regarding sexual behavior revealed the following: the age of first intercourse was 9-34 years, with a mean of 18.8 years; $80.7 \%$ of study participants had fewer than 3 sexual partners; $68 \%$ never use condoms, $47 \%$ practiced oral sex, $38 \%$ practiced anal sex, and $24.5 \%$ practiced both anal and oral sex; and among the 27 women who practiced oral sex, $15 \%$ always used condoms, $63 \%$ never did, and $22 \%$ occasionally used condoms. We did not determine whether condoms were used for vaginal, oral or anal sex. Two (3.5\%) women had genital warts, and $10 \%$ reported genital warts in their sexual partners.

With respect to habits, $5 \%$ smoked, $38 \%$ reported passive tobacco exposure, and 57\% drink alcohol.

To identify the factors associated with genital HPV, chi square analysis was performed excluding women infected with HPV type 13 (which is not a genital type) or non-typed HPV and women who had never had intercourse. None of the variables studied were associated with HPV infection (Table 2).

\section{Discussion}

The prevalence of oral HPV infection among women aged 14 to 69 years in Southeast Mexico is $14.8 \%$, a higher prevalence than has been reported by other (Smith et al., 2004; Kurose et al., 2004; Gillison et al., 2012). In this study, HPV13 was identified, which is a genotype considered to be exclusively oral; but was recently reported in the cervix (Illades-Aguiar et al., 2010; Tonani de Mattos et al., 2011). HPV13 was the most frequent genotype found in the study population ( $59.6 \%$ of all positive samples). If HPV 13 positive samples are excluded, the global prevalence of HPV was $6.1 \%$.

It bears mentioning that the discovery of HPV13 was fortuitous; the samples that could not be typed using oligonucleotides specific to genital types were sequenced using purified MY or GP amplicons. The sequencing results were further verified using primers specific to HPV13 (Cuberos et al., 2006).
Table 2 - Bivariate analysis of factors associated to genital HPV types infecting oral mucosa.

\begin{tabular}{lc}
\hline Variable & $\mathrm{p}$ \\
\hline *Age of first intercourse & 0.194 \\
**Total number of sexual partner & 0.295 \\
***Oral sex & 0.151 \\
Anal intercourse & 0.162 \\
Intercourse without protection & 0.164 \\
Sexual partner with genital warts & 0.984 \\
Woman with genital warts & 0.984 \\
Smoking & 0.659 \\
Passive tobacco exposure & 0.399 \\
Alcohol consumption & 0.734 \\
\hline
\end{tabular}

Only women with genital types were included. $\mathrm{N}=24$.

$* 18$ years $v s . \geq 18$ years, $* *$ number of sexual partners $\leq 2 v s . \geq 3, * * *$ active and passive.

This genotype was excluded from the bivariate analysis because as a non-genital type the risk factors associated to its acquisition and transmission are different to genital types, are not related to sexual behaviors, and is not considered oncogenic (Bascones-Martínez et al., 2012; HansUlrich et al., 2010)

HPV13 is a genotype associated with Multifocal Epithelial Hyperplasia (MEH), which is a rare pathology of the oral mucosa that has been described in some ethnic groups, principally in Americas (Cuberos et al., 2006). Our group has reported this pathology in Mayan locations in the Mexican southeast (Gonzalez-Losa et al., 2011; Lopez-Villanueva et al., 2011). In the present study, we found that $8.6 \%$ of the included participants were asymptomatically infected with this HPV type. The presence of HPV13 in subjects without lesions has been previously described (Cuberos et al., 2006; Lopez-Villanueva et al., 2011), although in closed communities and not open populations. Because evaluating this genotype was not one of our original objectives and was an unexpected finding, questionnaire did not include questions about a family or personal history of MEH, and therefore we cannot determine whether these are cases of clinical remission of the disease or cases that have always been asymptomatic. Studies of the natural evolution of this infection are not available.

MEH typically presents during the first decade of life. Asymptomatic infection among women 16-40 years of age could play a role in the transmission and maintenance of this virus in the community and within families; indeed, our group has identified HPV13 in asymptomatic relatives in families with MEH (Lopez-Villanueva et al., 2011). These findings suggest the need for longitudinal studies to increase our knowledge of the dynamics of HPV13 infection.

With respect to the other genotypes, the most frequent was the low risk HPV6, identified by sequencing, which was identified in 6 women. High risk genotypes $(16,58,59$ 
and/or 18) were found in $1.8 \%$ of the study population which is lower than what has been reported by other authors (Smith et al., 2004; Turner et al., 2011) but similar to our previous study of a group of odontology patients using High Risk Hybrid Capture 2 (Gonzalez-Losa et al., 2008) and higher than a large study conducted in the USA by Gillison (2012).

Data on oral HPV infections in healthy subjects in Mexico are limited; Kreimer (2010) conducted study that included 591 healthy Mexican men as part of a multinational investigation. The prevalence of HPV DNA was $5.9 \%$, and $1 \%$ of the study population was infected with high-risk HPV, with 16 being the most frequent. These data are similar to those found in this study.

Analyzing the distribution of genital HPV by age range, the group with highest prevalence of HPV ranged from 21 to 25 years $(18.2 \%$ ), results similar to those reported for HPV infections of the cervix. Gillison (2012) performed a large study in North America and reported two peaks in the prevalence of cervical infection: the first at age 25 years and the second at age 55 . This second increase was not found in our study. Overall, we found that women younger than 25 years old had the highest prevalence of HPV infection of the oral mucosa, which is similar to what is reported worldwide for cervical infection.

Finding HPV genital types in the oral cavity raised questions about possible routes of transmission, oral sex being one of the most likely. Therefore, sexual behaviors as risks factors have been the subject of research by several groups, although the evidence is limited. Smith et al. found that young persons with sexual behaviors clearly associated with sexual transmission of HPV have a higher prevalence of oral HPV than those who do not engage in risky sexual practices (Smith et al., 2004). Anaya-Saavedra (2008) conducted a case-control study in which age at the onset of sexual activity and the number of sexual partners was associated with oral infection with high-risk HPV types.

In this study, a statistical association between sexual behavior and oral infection with genital types of HPV was not found; similar results were reported in a large study of men (Kreimer et al., 2011).

In this study, oral HPV infection was detected during the first of round PCR for $36.8 \%$ of positive samples, whereas $63.2 \%$ required nested PCR. We assume that this indirectly reflects viral load. Interestingly, when investigating genotypes, $57 \%$ of HPV 13 positive samples were detected by MYs PCR (first round); in contrast, only $8 \%$ of samples infected with the other genotypes could be amplified using this PCR and required a nested reaction to detect the infection. Nested PCR is a much more sensitive technique, and therefore, samples that only amplify using this technique likely have a lower viral load. Quantitative PCR is required to confirm this hypothesis.

Current information about oral HPV infection is limited and incomplete. There are many questions to address, such as the following: what is the natural history of infection?; what factors are associated with oral HPV infection?; which factors are involved in the persistence of oral HPV infection?; what is responsible for the development of the oral neoplastic lesions associated with HPV? and what is the role of oral sex in the transmission of HPV?

Therefore, it is important to perform longitudinal studies in different populations as well as case-control studies.

\section{Acknowledgments}

We thank R.E. Suarez Allen for valuable technical support. Funding: Universidad Autónoma de Yucatán.

\section{References}

Anaya-Saavedra G, Ramírez-Amador V, Irigoyen-Camacho ME, García-Cuellar CM, Guido-Jiménez M, Mendez-Martinez R, Garcia-Carranca AL (2008) High Association of Human Papillomavirus Infection with Oral Cancer: A Case-Control Study. Arch Med Research 39:189-197.

Bascones-Martínez A, Cok S, Bascones-Ilundáin C, Arias-Herrera S, Gomez-Font R, Bascones-Ilundáin J (2012) Multifocal epithelial hyperplasia: A potentially precancerous disease? Oncol Letters 3:255-8.

Cuberos V, Perez J, Lopez CJ, Castro F, Gonzalez LV, Correa LA, Sanclemente G, Gaviria A, Müller M, Sanchez GH (2006) Molecular and serological evidence of the epidemiological association of HPV 13 with focal epithelial hyperplasia: A case-control study. J Clin Virol 37:21-26.

D'Souzaa G, Dempsey A (2011) The role of HPV in head and neck cancer and review of the HPV vaccine. Prev Med 53:S5-S11.

De Villers EM, Fauquet C, Broker T, Bernard H, Harald Z (2004) Classification of Papillomavirus. Virology 324:17-27.

Galvão Castro TPP. and Bussoloti Filho I (2006) Prevalence of human papillomavirus (HPV) in oral cavity and oropharynx. Rev Bras Otorrinolaringol 72:272-282.

Gillison ML, Broutian, Pickard RK, Tong Z, Xiao W, Kahle L, Graubard BI, Chaturvedi AK (2012) Prevalence of Oral HPV Infection in the United States, 2009-2010. JAMA 307:693-703.

Gonzalez-Losa, MR, Manzano-Cabrera L, Rueda-Gordillo F, Hernández-Solís S, Puerto-Solís, M (2008) Low prevalence of high risk human papillomavirus in normal oral mucosa by hybrid capture 2. Braz J Microbiol 39:32-34.

Gonzalez-Losa MR, Suárez-Allén RE, Canul-Canche J, CondeFerráez L, Eljure-López N (2011) Multifocal epithelial hyperplasia in a community of the Mayan area of Mexico. Int J Dermatol 50:304-309.

Hans-Ulrich B, Burk RD, Chen Z, van Doorslaer K, zur hausen H, de Villers EM (2010) Classification of papillomavirus (PVs) based on 189 types and proposal of taxonomic amendments. Virology 401:70-79.

Illades-Aguiar B, Alarcón-Romero LC, Antonio-Véjar V, Zamudio-López N, Sales-Linares N, Flores-Alfaro E (2010) Prevalence and distribution of human Papillomavirus types in cervical cancer, squamous intraepithelial lesions, and with no intraepithelial lesions in women from Southern Mexico. Gynecol Oncol 117:291-296. 
Khalili J (2008) Oral cancer: Risk factors, prevention and diagnostic. Exp Oncol 30:259-264.

Kreimer AR, Villa A, Nyitray AG, Abrahamsen M, Papenfuss M, Smith D, Hildesheim A, Villa L, Lazcano-Ponce E, Giuliano AR (2011) The epidemiology of oral HPV infection among a multinational sample of healthy men. Cancer Epidemiol Biomarkers Prev 20:172-182.

Kurose K, Terai M, Soedarsono NN, Rabello D, Nakajima Y, Burk RD (2004) Low prevalence of HPV infections and its natural history in normal oral mucosa among volunteers on Mikako Island, Japan. Oral Surg Oral Med Oral Pathol Oral Radiol Endod 98:91-96.

Lazcano-Ponce E, Herrero R, Muñoz N, Cruz A, Shah K, Alonso P, Hernández P (2001) Epidemiology of HPV infection among Mexican women with normal cervical cytology. Int J Cancer 91:412-420.

Lizano-Soberón M, Carrillo-García A, Contreras-Peredes, A (2009) Infección por virus del Papiloma Humano: Epidemiología, Historia Natural y Carcinogénesis. Cancerología 4:205-216.

López -Saavedra, A. and Lizano-Soberón, M (2006) Cáncer cervicouterino y el virus de Papiloma humano: La historia que no termina. Cancerología 1:31-55.

López-Villanueva M.E, Conde-Ferraez L, Ayora-Talavera G, Cerón-Espinosa J, González-Losa MR (2011) Human papillomavirus 13 in a Mexican Mayan community with multifocal epithelial hyperplasia: could saliva be involved in household transmission? Eur J Dermatol 21:396-400.

Mao L, Ki Hong W (2004) How does human papillomavirus contribute to head and neck cancer development? J Natl Cancer Inst 96:978-980.
Qu W, Jiang G, Cruz Y, Chang CJ, Ho GY, Klein RS, Burk RD (1997) PCR detection of human papillomavirus: comparison between MY09/11 and GP51/61 primer system. J Clin Microbiol 35:1304-1310.

Saiki RK, Scharf S, Faloona F, Mullis KB, Horn GT, Erlich HA, Arnheim N (1985) Enzymatic amplification of beta-globin genomic sequences and restriction site analysis for diagnosis of sickle cell anemia. Science 230:1350-1354.

Smith EM, Ritchie JM, Summersgill KF, Hoffman HT, Hong Wang D, Haugen HT, Turek LP (2004) Human Papillomavirus in oral exfoliated cells and risk of head and neck cancer. J Natl Cancer Inst 96:445-455.

Sotlar K, Diemer D, Dethleffs A, Hack Y, Stubner A, Vollmer N (2004) Detection and typing of human papillomavirus by E6 nested multiplex PCR. J CLIN Microbiol 42:3176-3184.

Tonani de Mattos A, Bueno de Freitas L, Coelho Lima B, Espinosa Miranda A, Cruz Spano L (2011) Diversity and uncommon HPV types in HIV seropositive and seronegative women attending an STI Clinic. Braz J Microbiol 42:786793.

Turner DO, Williams-Cocks SJ, Bullen R, Catmull J, Falk J, Martin D, Maue J, Barber AE, Wang RC, Gerstenberger SL, Kingsle K (2011) High-risk human papillomavirus (HPV) screening and detection in healthy patient saliva samples: a pilot study. BMC Oral Health. http://www.biomedcentral.com/1472-6831/11/28.

Walboomers JMM, Jacobs MV, Manos MM, Bosch FX, Kummer JA, Shah KV, Snijders PJ, Peto J, Meijer CJ, Muñoz N (1999) Human Papillomavirus is a necessary cause of invasive cervical cancer worldwide. J Pathol 189:12-19.

Associate Editor: Maurício Lacerda Nogueira

All the content of the journal, except where otherwise noted, is licensed under a Creative Commons License CC BY-NC. 